\title{
OS EFEITOS DA ESTIMULAÇÃO SENSÓRIO MOTORA ORAL NA SUCÇÃO NUTRITIVA NA MAMADEIRA DE RECÉM-NASCIDOS PRÉ-TERMO
}

\author{
The sensory-motor-oral stimulation effects \\ on nutritive sucking of preterm infants during bottle feeding
}

\author{
Raquel Coube de Carvalho Yamamoto (1), Magda Aline Bauer (2), Leris Salete Bonfanti Häeffner (3), \\ Ângela Regina Maciel Weinmann ${ }^{(4)}$, Márcia Keske-Soares ${ }^{(5)}$
}

\begin{abstract}
RESUMO
Objetivo: verificar o desempenho da sucção nutritiva, na mamadeira, em recém-nascidos pré-termo submetidos à estimulação sensório-motora-oral. Métodos: pesquisa do tipo ensaio clínico controlado de intervenção. 20 recém-nascidos pré-termo foram distribuídos em grupo estimulado e grupo controle. Estes grupos foram submetidos à avaliação fonoaudiológica em dois diferentes momentos: na liberação da alimentação por via oral; e quando atingiam alimentação plena por via oral num período de 24 horas. As avaliações foram filmadas, e os resultados foram analisados pela pesquisadora. Para análise dos dados utilizou-se o Teste exato de Fisher e o Teste "T" de Student do software estatístico STATA 10.0. Considerou-se $p<0,05$. Resultados: recém-nascidos do grupo estimulado, na segunda avaliação, apresentaram resultados com diferença estatística significante quanto a força de sucção forte $(p=0,003)$, presença dos três reflexos adaptativos $(p=0,001)$, coordenação da sucção/deglutição/ respiração $(p=0,003)$, no tempo total de sucções $(p=0,01)$ e na frequência de sucção $(p<0,01)$. 0 número total de sucções apresentou diferença estatística significante $(p<0,05)$ entre as avaliações do grupo controle. Quanto ao ritmo e a relação entre o volume de leite prescrito e ingerido não apresentou resultados com diferença estatística significante. Conclusão: a estimulação sensório-motora oral parece favorecer o desempenho nas funções de sucção nutritiva de recém-nascidos pré-termo.
\end{abstract}

DESCRITORES: Recém-Nascido; Prematuro; Alimentação; Sucção

(1) Fonoaudióloga; Atendimento hospitalar e domiciliar; Mestre em Distúrbios da Comunicação Humana pela Universidade Federal de Santa Maria.

(2) Fonoaudióloga; Atendimento clínico e domiciliar; Mestre em Distúrbios da Comunicação Humana pela Universidade Federal de Santa Maria.

(3) Médica Pediatra; Professora do Curso de Medicina da Universidade Federal de Santa Maria, UFSM, Santa Maria, RS; Doutora pela Faculdade de Medicina de Ribeirão Preto da Universidade de São Paulo.

(4) Médica Neonatologista; Professora do Curso de Medicina e do Programa de Pós-graduação em Distúrbios da Comunicação Humana da Universidade Federal de Santa Maria, UFSM, Santa Maria, RS; Doutora pela Faculdade de Medicina de Ribeirão Preto da Universidade de São Paulo; Pós-Doutorado no The Sick Children Hospital, University of Toronto, Canadá.

(5) Fonoaudióloga; Professora do Curso de Fonoaudiologia e do Programa de Pós-graduação em Distúrbios da Comunicação Humana da Universidade Federal de Santa Maria, UFSM, Santa Maria, RS; Bolsista de Produtividade em Pesquisa 2 do Conselho Nacional de Desenvolvimento Científico e Tecnológico, CNPq; Doutora em Linguística Aplicada pela Pontifícia Católica do Rio Grande do Sul.

Conflito de interesses: inexistente

\section{INTRODUÇÃO}

A função de sucção é de extrema importância na vida do recém-nascido e, intra-útero, sua ocorrência já pode ser observada por volta da $15^{\underline{a}}$ a $18^{\text {a }}$ semana de gestação. Em ambiente extra-útero, movimentos de sucção podem ser observados na $27^{\text {a }}$ semana de idade gestacional corrigida, embora ainda ocorram de forma desorganizada. A sucção começa a se organizar a partir da $32^{\text {a }}$ semana de idade gestacional corrigida, porém, sem estabilidade rítmica. Esta estabilidade ocorre por volta da $34^{\text {a }}$ semana ${ }^{1}$. A estabilidade neuromuscular ocorrerá nos recém-nascidos saudáveis quando estes estiverem com uma idade gestacional corrigida de 36 semanas $^{2}$.

A idade gestacional corrigida é um dos critérios utilizados para que se dê início à alimentação por via oral em recém-nascidos pré-termo (RNPT), 
variando, conforme descrito na literatura, de 32 a 34 semanas ${ }^{3}$. Diante disso, a alimentação oral não deve ter início nos RNPT que apresentem uma idade gestacional corrigida inferior a 32 semanas ${ }^{1}$, por não apresentarem estabilidade neuromuscular adequada para coordenar as funções de sucçãodeglutição-respiração (S/D/R) durante a mamada ${ }^{4}$. Por essas razões, os RNPT precisam ser alimentados por meio da sonda até estarem aptos para iniciar a alimentação por via oral ${ }^{5-7}$.

O uso de sonda tem como consequência, geralmente, um atraso na organização da sucção nutritiva (SN) devido à falta de estímulos sensoriais. A ausência de estímulos pode afetar o desenvolvimento motor-oral, que por sua vez sofrerá melhora, na dependência do aumento da idade gestacional corrigida do recém-nascido ${ }^{8-11}$ e da própria SN. A SN pode ser feita por meio da oferta do seio materno ou utilizando a mamadeira com a presença de líquido quando o recém-nascido já está apto para alimentar-se por via oral ${ }^{12}$.

À medida que a SN se organiza, a frequência de sucção vai estabilizando, os blocos vão ficando maiores, os números de sucções por minuto diminuem e, além disso, observa-se um declínio da taxa de sucção devido às variações das pausas ${ }^{1,13}$.

Durante a SN, o líquido movimenta-se devido à presença da pressão intra-oral que é gerada. Com a presença do líquido tem-se a necessidade de que ocorram deglutições, com isso, a taxa de sucção da SN apresenta-se mais lenta que a taxa da sucção não-nutritiva (sucção sem a presença de alimento). Ao contrário desta, a SN organiza-se com padrões rítmicos contínuos com pequenas alterações nos blocos de sucção ${ }^{12}$ que ocorrem quando o RN realiza um conjunto de sucções durante um período de tempo ininterrupto.

O RNPT tem dificuldade em coordenar a respiração durante a alimentação por via oral, sendo o ritmo de maturação desse processo ainda desconhecido. Por esta razão, a alimentação no período neonatal é uma atividade bastante complexa, uma vez que exige uma eficiente coordenação entre $\mathrm{S} / \mathrm{D} / \mathrm{R}^{14}$.

Um RNPT apresenta coordenação entre a S/D/R tão eficiente quanto a de um recém-nascido a termo quando estiver próximo da $37^{\text {a }}$ semana de idade gestacional corrigida ${ }^{15}$. Um ciclo considerado perfeito e coordenado para a S/D/R ocorre quando há uma sequência padrão de 1:1:1 ${ }^{16}$. Considerando a sucção e a deglutição, acredita-se que exista coordenação entre estas quando a taxa seja, em média, de 1:1 sucção/deglutição para um mesmo período de tempo, tanto para RNPT como para os de termo 8,17 , tanto na alimentação na mamadeira quanto no seio materno.
Considerando apenas a sucção, os estudos mostram também a influência da idade gestacional corrigida sobre a mesma. Um estudo aponta que, durante a alimentação no seio materno, RNPT de idade gestacional igual ou inferior a 30 semanas, os blocos de sucção, na SN, variaram de 1 a 5 sugadas; para os com IG entre 31 e 32 semanas a variação foi de 6 a 15 sugadas; e, igual ou maior de 33 semanas os blocos apresentaram mais de 15 sucções ${ }^{17}$. No entanto, este parâmetro para a sucção nutritiva na mamadeira não foi encontrado para fins de comparação com os resultados da presente pesquisa.

Mesmo que a maturação fisiológica seja um fator primordial ao desenvolvimento do processo de coordenação entre S/D/R, alguns estudos ${ }^{11,18-20}$ têm demonstrado a influência da estimulação sensório-motora-oral sobre o desempenho alimentar do RNPT. A estimulação, além de influenciar positivamente o processo normal de maturação, poderia contornar as dificuldades surgidas em decorrência dos prolongados períodos de uso de sonda e ventilação mecânica.

Assim, esta pesquisa teve como objetivo verificar o desempenho da sucção nutritiva, na mamadeira, em recém-nascidos pré-termo submetidos à estimulação sensório-motora-oral.

\section{MÉTODOS}

Realizou-se um estudo analítico, do tipo ensaio clínico controlado de intervenção ${ }^{21}$, incluindo 20 RNPT, no período de maio de 2007 a março de 2008 e internadas na UTI Neonatal do Hospital Universitário de Santa Maria (HUSM).

Foram incluídos na pesquisa recém-nascidos internados na unidade neonatal, com idade gestacional entre 26 e 33 semanas (Método New Ballard), adequado ou pequeno para a idade gestacional e que não tinham recebido a ingestão de alimento por via oral. Foram excluídos os recém-nascidos com malformações de cabeça e pescoço, síndromes genéticas, hemorragia intracraniana diagnosticada por ultra-sonografia de crânio, asfixia perinatal definida pela presença de Apgar de 5 minuto menor ou igual a 5 e encefalopatia bilirubínica diagnosticada pela equipe médica. Todos os RNPT participantes foram alimentados utilizando mamadeira, uma vez que as mães não apresentarem desejo em amamentar, fato causado provavelmente pela pouca produção de leite em consequência do longo período de afastamento do binômio mãe-filho.

Ao entrar no estudo os RNPT foram distribuídos em dois grupos mediante sorteio em estimulado (GE) e controle (GC). A coleta de dados era iniciada quando o RNPT atingisse uma dieta enteral de 
$80 \mathrm{cal} / \mathrm{kg} / \mathrm{dia}$, administrada por meio de sonda orogástrica, estando clinicamente estável. Ambos os grupos não fizeram uso de qualquer tipo de chupeta antes e durante a participação na pesquisa.

Tanto o GE quanto o GC realizaram a avaliação fonoaudiológica em dois diferentes momentos: na liberação da alimentação por via oral (1 $1^{a}$ avaliação fonoaudiológica); e quando atingiam alimentação plena por via oral num período de 24 horas ( $2^{\mathrm{a}}$ avaliação fonoaudiológica). As avaliações fonoaudiológicas foram realizadas por fonoaudiólogas participantes da pesquisa, experientes na atuação com RNPT, sendo estas que também efetuaram as estimulações fonoaudiológicas diariamente.

A estimulação sensório-motora-oral ${ }^{18}$ era composta por massagens extra e intra-orais, além da estimulação da sucção não-nutritiva, utilizando o dedo enluvado. A frequência foi duas vezes ao dia (uma no período da manhã, em torno das 8 horas, e outra à tarde, em torno das 17 horas), antes da alimentação por sonda, durante 15 minutos, os 7 dias da semana. Os profissionais da Unidade Neonatal envolvidos com os RNPT não sabiam da existência da divisão em GC e GE, pois os RNPT do GC recebiam uma estimulação simulada de modo que a equipe não soubesse a que grupo o recém-nascido pertencia, para não criar expectativa quanto ao desempenho alimentar apresentado pelo RNPT no decorrer da sua hospitalização ${ }^{22}$.

O programa de estimulação foi adaptado quanto ao proposto no protocolo original ${ }^{18}$, pois se utilizou o dedo enluvado do avaliador ao invés da chupeta na estimulação da sucção não-nutritiva. Tal modificação foi definida pelas pesquisadoras por dois motivos: questionamentos que poderiam ser gerados por parte dos profissionais envolvidos quanto à regra do não uso de chupeta nos demais horários; e para que o avaliador tivesse melhor percepção quanto aos aspectos e desempenho intra-oral dos RNPT no momento da estimulação/avaliação.

A mamadeira utilizada era da marca Fiona, e bico comum de látex para todos os RNPT que participaram deste estudo. A equipe de auxiliares técnicos eram as que administravam a dieta por via oral. Cabe salientar que as mamadas foram filmadas, para posterior coleta e análise das informações necessárias.

A avaliação fonoaudiológica realizada utilizou itens selecionados de protocolo elaborado com base em outras pesquisas ${ }^{23-25}$, no que se refere a aspectos da SN, que foram: presença dos três reflexos orais adaptativos (busca, sucção e deglutição), força e ritmo de sucção, presença de blocos de sucção, número e tempo de sucções por bloco, frequência de sucção (relação entre o número pelo tempo de sucção), tempo das pausas entre os blocos e presença de coordenação da S/D/R durante a mamada.

A força de sucção foi caracterizada pela resistência que o avaliador encontrava ao tentar retirar a mamadeira da boca do recém-nascido ${ }^{25}$, durante a SN. Considerava-se forte quando existia grande resistência na retirada do instrumento usado, e fraca quando se conseguia retirar com pouca ou nenhuma resistência. Esse dado foi observado e anotado no momento da realização da avaliação, não através de filmagem como os demais itens. A presença de ritmo de sucção foi caracterizada avaliando os blocos de sucções alternados por pausas. As pausas respiratórias observadas entre os blocos de sucção foram consideradas quando o recémnascido apresenta um tempo igual ou superior 2 segundos ${ }^{8,14}$.

Para avaliação dos blocos de sucção foram considerados os cinco primeiros blocos. O tempo dos blocos de sucções, assim como a pausa entre os blocos foram cronometrados utilizando-se um cronômetro manual de marca Mondaine. A fim de confirmar os achados, as avaliações fonoaudiológicas foram filmadas utilizando-se filmadora da marca Sony, modelo DCR-SR42. As filmagens foram analisadas pela pesquisadora e re-analisadas pela mesma por, no mínimo, duas vezes em diferentes momentos para confirmar os valores encontrados. Não houve avaliação por pares.

O protocolo de investigação foi aprovado pelo Comitê de Ética em Pesquisa da Instituição sob o número $n^{\circ}$ 0131.0.243.000-06 e o Termo de Consentimento Livre e Esclarecido foi assinado pelos pais ou representantes legais.

A análise dos dados foi feita através do software STATA 10, utilizando estatística descritiva e a medida de tendência central média. Para os dados não paramétricos foi usado o Teste Exato de Fishere para a diferença entre as médias, o teste t de Student. Considerou-se como significante a obtenção de um valor de $p<0,05$.

\section{RESULTADOS}

A sucção nutritiva foi avaliada em 20 RNPT divididos em dois grupos, um estimulado e outro controle. A Tabela 1 apresenta os aspectos da SN, em ambos os grupos, nos dois momentos avaliados. Observa-se que o GE na $2^{a}$ avaliação apresentou um percentual maior de força de sucção forte $(p=0,003)$, presença dos três reflexos adaptativos $(p=0,001)$ e coordenação da $S / D / R(p=0,003)$ em relação a $1^{\text {a }}$ avaliação e ambas as avaliações do GC. Com relação ao ritmo não houve diferença entre os grupos. 
Tabela 1-Aspectos da sucção nutritiva na mamadeira na primeira e segunda avaliação fonoaudiológica no grupo controle e grupo estimulado

\begin{tabular}{|c|c|c|c|c|}
\hline \multirow[t]{2}{*}{ Variáveis } & \multicolumn{2}{|c|}{$\begin{array}{c}\text { Grupo Controle } \\
\text { M (dp) }\end{array}$} & \multicolumn{2}{|c|}{$\begin{array}{c}\text { Grupo Estimulado } \\
\text { M (dp) }\end{array}$} \\
\hline & $1^{\circ}$ Avaliação & $2^{\circ}$ Avaliação & $1^{\circ}$ Avaliação & $2^{\circ}$ Avaliação \\
\hline \multicolumn{5}{|l|}{ Blocos de Sucção" } \\
\hline $\begin{array}{l}N^{\circ} \text { total de sucções } \\
\text { (sucções) }\end{array}$ & $37,6( \pm 22,7)^{a}$ & $57,6( \pm 27,2)^{a}$ & $47,7( \pm 35,8)$ & $42,9( \pm 24,9)$ \\
\hline $\begin{array}{l}\text { Tempo total das Sucções } \\
\text { (segundos) }\end{array}$ & $44,8( \pm 27,3)^{a}$ & $64,3( \pm 31,3)^{a / b}$ & $51,9( \pm 41,3)^{a}$ & $36,8( \pm 20,2)^{a / b}$ \\
\hline $\begin{array}{l}\text { Freqüência de sucção } \\
\text { (sucções/segundos) }\end{array}$ & $0,8( \pm 0,3)$ & $0,9( \pm 0,1)^{b}$ & $0,9( \pm 0,4)$ & $1,2( \pm 0,3)^{b}$ \\
\hline $\begin{array}{l}\text { Total das pausas } \\
\text { (segundos) }\end{array}$ & $33,8( \pm 29,6)$ & $35,4( \pm 12,7)$ & $35,8( \pm 29,2)$ & $35,3( \pm 10,9)$ \\
\hline Volume prescrito" (ml) & $28,2( \pm 7,4)$ & $38,2( \pm 6,2)$ & $31,5( \pm 3,9)$ & $36,9( \pm 7)$ \\
\hline Volume ingerido" (ml) & $9,5( \pm 7,1)$ & $38,2( \pm 6,2)$ & $12,5( \pm 7,9)$ & $36,9( \pm 7)$ \\
\hline
\end{tabular}

*Teste realizado: Exato de Fisher $-\mathrm{N}(\%)$ : $n^{\circ}$ recém-nascido (porcentagem) $-p<0,05$

${ }^{a}$ diferença estatística significante entre as avaliações

O número total de sucções (Tabela 2) presente nos cinco primeiros blocos de sucção foi em média 37,6 e 57,6 sucções no GC e 47,7 e 42,9 sucções no GE na $1^{\mathrm{a}}$ e $2^{\mathrm{a}}$ avaliação, com diferença estatística significante entre as avaliações do GC. Quanto ao tempo total de sucções, pode-se observar que o GE apresentou média de 36,8 segundos, quase a metade do tempo, quando comparado ao GC com 64,3 segundos na $2^{a}$ avaliação, apresentando diferença estatisticamente significante $(p=0.01)$. Nessa mesma variável, resultados com diferença estatística significante, também foram observados nas médias entre as avaliações realizadas em ambos os grupos $(p<0,05)$. Pode-se observar que o $G C$, na $1^{\text {a }}$ avaliação, apresentou resultado inferior ao apresentado na $2^{\mathrm{a}}$ avaliação; e nota-se que no GE acontece o inverso, sendo que o resultado obtido na $1^{\text {a }}$ avaliação estava maior do que na segunda.

$\mathrm{Na}$ frequência de sucção (Tabela 2), a relação entre o número de sucções em função do tempo, na $2^{\mathrm{a}}$ avaliação, o GE apresentou em média 1,2 sucções por segundo, enquanto que o GC apresentou média de 0,9 sucções/segundo. Esse resultado apresentou diferença estatística significante $(p<0,01)$. No que se refere ao desempenho no momento da $1^{\text {a }}$ avaliação fonoaudiológica, pode-se observar que os RNPT do GC ingeriram em média um volume de $9,5 \mathrm{ml}$, enquanto que os do GE ingeriram $12,5 \mathrm{ml}$. A relação entre essas variáveis não apresentou diferença estatística significante.

Na Figura 1 é possível observar o desempenho dos RNPT do GC e GE na $1^{a}$ e $2^{a}$ avaliação fonoaudiológica nos cinco blocos de sucção avaliados. As variáveis observadas nos blocos foram: número de sucções $(A)$, tempo das sucções $(B)$ e a pausa entre os blocos de sucção $(C)$.

\section{DISCUSSÃO}

No presente estudo, no momento da liberação para a via oral, os RNPT tanto do GE como do GC apresentavam-se semelhantes quanto à força de sucção, ritmo de sucção, presença dos três reflexos adaptativos, coordenação da S/D/R e presença de blocos de sucção. Quando comparada a $1^{\underline{a}}$ com a $2^{\mathrm{a}}$ avaliação fonoaudiológica entre os grupos específicos, o GE apresentou diferença estatística significante entre as variáveis: força de sucção, presença dos três reflexos adaptativos e coordenação da S/D/R. Esses resultados denotam a eficiência do programa de estimulação para esses RNPT.

As diferenças estatísticas significantes quanto ao número total de sucção nas avaliações feitas no GC, e o tempo total de sucção quando comparado GC e GE na $2^{a}$ avaliação, e também entre os grupos sugerem a ingestão de um volume maior de leite observado no GE, na liberação da via oral. Esses valores confrontados com a literatura ${ }^{2}$ sugerem que os RNPT do GE apresentavam-se melhor organizados nos blocos de sucção, conforme o esperado para a idade gestacional corrigida apresentada, bem como pela estimulação sensório-motora-oral realizada previamente à liberação da via oral.

A maior ingestão do volume de leite, ofertado pela mamadeira, observada nas crianças do GE também pode ser reflexo da estimulação sensóriomotora-oral, sugerindo que os mesmos estivessem mais aptos, sendo capazes de ingerir uma quantidade maior de leite, na liberação da via oral. 
Tabela 2 - Média e desvio padrão do número e tempo total das sucções, frequência de sucção e total das pausas dos blocos de sucção, volume prescrito e ingerido em relação ao grupo controle e grupo estimulado

\begin{tabular}{|c|c|c|c|c|}
\hline \multirow[t]{2}{*}{ Variáveis } & \multicolumn{2}{|c|}{$\begin{array}{c}\text { Grupo Controle } \\
\text { N (\%) }\end{array}$} & \multicolumn{2}{|c|}{$\begin{array}{c}\text { Grupo Estimulado } \\
\text { N (\%) }\end{array}$} \\
\hline & $1^{\circ}$ Avaliação & $2^{\circ}$ Avaliação & $1^{\circ}$ Avaliação & $2^{\circ}$ Avaliação \\
\hline \multicolumn{5}{|l|}{ Força de sucção* } \\
\hline Forte & $5(50)$ & $6(60)$ & $4(40)^{a}$ & $9(90)^{a}$ \\
\hline Fraco & $5(50)$ & $4(40)$ & $6(60)$ & $1(10)$ \\
\hline \multicolumn{5}{|l|}{ Ritmo de sucção* } \\
\hline Presente & $3(30)$ & $7(70)$ & $4(40)$ & $6(60)$ \\
\hline Ausente & $7(70)$ & $3(30)$ & $6(60)$ & $4(40)$ \\
\hline \multicolumn{5}{|c|}{ Reflexos orais adaptativos* } \\
\hline 3 reflexos presentes & $6(60)$ & $7(70)$ & $7(70)^{\mathrm{a}}$ & $9(90)^{a}$ \\
\hline$<3$ reflexos presentes & $4(40)$ & $3(30)$ & $3(30)$ & $1(10)$ \\
\hline \multicolumn{5}{|l|}{ Coordenação S/D/R* } \\
\hline Presente & $7(70)$ & $7(70)$ & $6(60)^{a}$ & $9(90)^{a}$ \\
\hline Ausente & $3(30)$ & $3(30)$ & $4(40)$ & $1(10)$ \\
\hline \multicolumn{5}{|l|}{ Blocos de sucção* } \\
\hline Presente & $9(90)^{\mathrm{a}}$ & $10(100)^{a}$ & $9(90)^{\mathrm{a}}$ & $10(100)^{a}$ \\
\hline Ausente & $1(10)$ & $0(0)$ & $1(10)$ & $0(0)$ \\
\hline
\end{tabular}

"Teste realizado: "T" de Student $-M(d p)$ : Média (desvio padrão) $-p<0,05$

a diferença estatística significante entre as avaliações

${ }^{\text {b }}$ diferença estatística significante entre os grupos na mesma avaliação

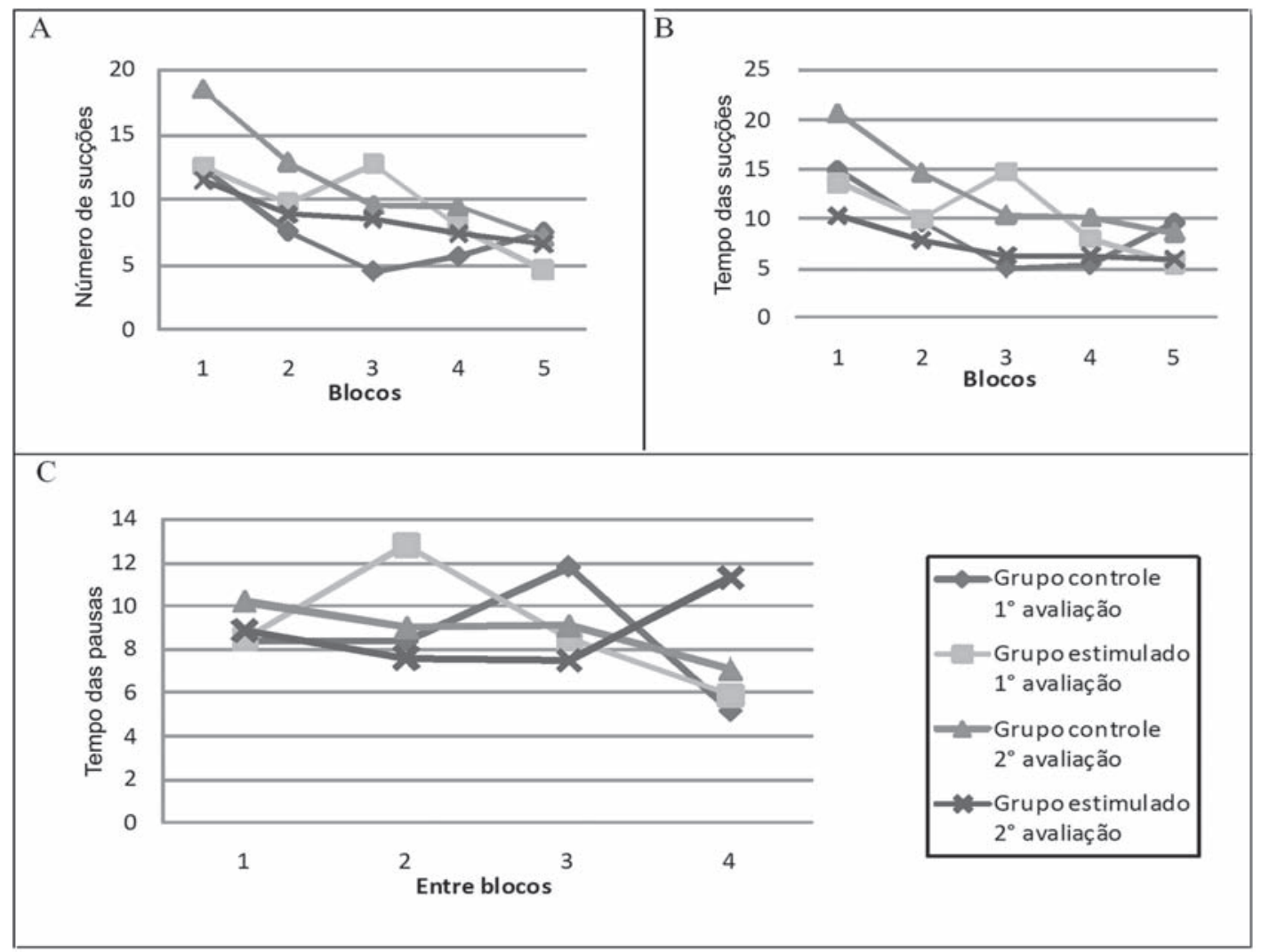

Figura 1 - Características dos blocos de sucção quanto ao número de sucções $(A)$, tempo das sucções (B) e pausas entre os blocos de sucção (C) 
A observação de que no GE os RNPT apresentaram maior força de sucção, maior percentual de presença dos reflexos adaptativos e de coordenação da $S / D / R$, sugere que a estimulação sensóriomotora-oral resultou em melhoria da sucção destas crianças. A menor evolução apresentada pelo GC, provavelmente esteja relacionada à própria maturidade esperada e que foi alcançada pelos RNPT mesmo sem estimulação, concordando com diversos autores ${ }^{3,4,6,7,14,26}$. Um estudo ${ }^{19}$ comenta que 0 programa de estimulação pode acelerar a maturação e a coordenação dos músculos usados na sucção.

Quanto ao aspecto força de sucção, a idade gestacional teria maior relevância do que o peso para apresentar força de sucção forte na $\mathrm{SN}{ }^{27}$. Para que ocorra uma alimentação por via oral de maneira adequada, é necessário que o recémnascido apresente uma relação rítmica e coordenada entre a S/D/R, pois a estabilidade rítmica, que decorre do crescente equilíbrio entre o ritmo de sucção e a relação entre sucção/deglutição, é um sinal de maturidade no decorrer do processo de alimentação ${ }^{11,14,15,26}$.

A eficiência da alimentação oral melhora com o aumento da frequência de sucção e deglutição, com a quantidade do bolo alimentar, e com o aumento da amplitude de sucção ${ }^{15}$, sendo a coordenação da S/D/R crucial para a segurança da alimentação oral ${ }^{15,28}$ e ela aparece com a maturidade ${ }^{14,26,27,29}$, o que não ocorre com os RNPT por apresentar uma coordenação alterada ${ }^{8,30}$.

Pode-se observar que tanto os RNPT do GE quanto os do GC apresentaram blocos de sucção, deduzindo-se assim que estavam prontos para realizar a função de sucção. Os RNPT do GC apresentaram maior número de sucção por bloco, quando comparado com o GE, podendo-se inferir que os mesmos necessitaram realizar um número total de sucções maior para conseguir ingerir o conteúdo da mamadeira, enquanto que o GE apresentou um número total de sucções menor, porém, com mais eficiência na sucção. Estes resultados estão de acordo com outra pesquisa que afirma que a prática com a alimentação pode resultar numa maturação mais rápida nos aspectos da sucção ${ }^{31}$.

Outro estudo ${ }^{17}$ constatou que a SN das crianças nascidas com idade gestacional igual ou inferior a 30 semanas variou de 1 a 5 sugadas, entre 31 e 32 semanas variou de 6 a 15 sugadas e, em três crianças com idade gestacional maior ou igual a 33 semanas, mais de 15 sucções por bloco.

Esses dados não coincidem com os encontrados para o GC e GE, que apresentaram média da idade gestacional corrigida de 34,6 e 35 semanas, respectivamente, e com blocos de sucção de
4,4 a 12,4 sucções para o GC e de 4,6 a 12,8 para o GE no momento da liberação da via oral, correspondendo aos valores encontrados nos RNPT de 31 a 32 semanas no estudo supracitado. Convém ressaltar que nesse caso, a sucção foi realizada no seio materno, com padrões distintos da sucção na mamadeira do presente estudo e já relatada pela literatura.

No tempo total de sucções, os RNPT do GE apresentaram quase a metade do tempo levado para o GC, com resultado estatisticamente significante, demonstrando que a estimulação sensóriomotora-oral parece ter beneficiado o desempenho de SN na mamadeira dos RNPT do GE.

Quando analisado o número total de sucções e o tempo total de sucções de ambos os grupos, observa-se que o GE necessitou de menor número de sucções e, de quase a metade do tempo dessas sucções para ingerir todo o volume prescrito. Este dado mostra que o GE apresentava-se mais eficiente na função de SN na mamadeira quando comparado ao GC.

$\mathrm{Na}$ frequência de sucção, observou-se que os RNPT do GE apresentaram melhor desempenho quando obtiveram a via oral plena. Pesquisa ${ }^{2}$ realizada sem influência da estimulação sensóriomotora-oral observou um comportamento com duração da sucção de 0,$57 ; 0,69$ e 0,71 segundos, para as idades gestacionais corrigidas de 34,35 e 36 semanas, respectivamente, dados próximos ao encontrado nesta pesquisa pelo GC. Esses achados sugerem que a estimulação pode ter influenciado no melhor desempenho da frequência de sucção dos RNPT do GE, concordando com outra pesquisa ${ }^{32}$ que indica que, além do peso e da idade gestacional corrigida apresentado pelo RNPT, as habilidades motoras orais, a prática alimentar e as técnicas de alimentação contribuem para um adequado desempenho alimentar.

As semelhanças nas pausas por bloco e o total de pausas entre os dois grupos denota que a associação dessas variáveis com a SN na mamadeira possa não existir, principalmente pelo critério utilizado pela equipe médica para a transição alimentar ter sido a idade gestacional corrigida e peso apresentado pelo RNPT. Tal achado pode ser justificado pelo o critério para transição da alimentação por sonda para mamadeira ter sido prescrito e indicado pela equipe médica, desconsiderando aspectos do funcionamento do sistema sensório motor oral. Atualmente já existe protocolo validado que indica com precisão o momento para iniciar de modo seguro a transição da alimentação por via oral de forma objetiva, considerando aspectos gerais e específicos da sucção não-nutritiva do RNPT ${ }^{28}$. 
Pode-se observar que o programa de estimulação sensório-motora-oral apresentou influências tanto nos aspectos mais objetivos da avaliação (tempo de sucções, frequência de sucções, pausas) quanto nas variáveis mais subjetivas (força e ritmo de sucção, presença dos reflexos, coordenação da $\mathrm{S} / \mathrm{D} / \mathrm{R})$. Denotando que a estimulação beneficiou o desempenho da função de sucção dos RNPT do GE.

Acredita-se que talvez um programa de estimulação, direcionado às necessidades sensóriomotora-orais do RNPT e treino da sucção, utilizando a sucção não-nutritiva, pudessem promover melhores resultados. A maior limitação encontrada nesta pesquisa foi o reduzido tamanho amostral. Entretanto, os achados sugerem a necessidade de se realizarem novas pesquisas, dando maior enfoque ao sensório motor oral do RNPT e na sucção não-nutritiva.

\section{CONCLUSÃO}

A estimulação sensório-motora-oral parece favorecer o desempenho nas funções de sucção nutritiva na mamadeira de recém-nascidos pré-termo, principalmente em relação a melhorar a força de sucção, a presença dos três reflexos adaptativos e a coordenação da sucção-deglutição-respiração. Assim, considera-se que a estimulação sensóriomotora-oral pode favorecer o desempenho nas funções de sucção do recém-nascido pré-termo e a própria nutrição do mesmo.

\begin{abstract}
Purpose: to check the nutritive sucking performance in preterm infants that underwent sensory-motororal stimulation. Methods: a controlled clinical trial of intervention was performed in 20 preterm infants divided into experimental and control group. The infants received a speech therapist evaluation in two different times: at the beginning of the oral feeding (first speech therapist evaluation) and when they reached full oral feeding (second evaluation). Statistical data analyses used STATA 10 package and they were analyzed for treatment group differences with Fisher's exact Test and Student's unpaired $t$-test $(p<0.05)$. Results: infants in the experimental group, in the second evaluation, differed statistically in the pressure of strong sucking $(p=0.003)$, presence of the three adaptive reflexes $(p=0.001)$, coordination among sucking, swallowing and breathing $(p=0.003)$, the total time for sucking $(p=0.01)$ and of number of sucking/time $(p<0.01)$. The total number of sucks showed a statistically significant difference $(p<0.05)$ among the evaluations of the control group. No differences were observed among the groups as for sucking rhythm, and prescribed and ingested milk volume. Conclusion: in this study, sensory-motor-oral stimulation contributed for a better sucking performance, during bottle feeding, in preterm infants.
\end{abstract}

KEYWORDS: Infant, Newborn; Premature; Feeding; Suction

\section{REFERÊNCIAS}

1. Wolff $\mathrm{PH}$. The serial organization of sucking in the young infant. Pediatrics. 1968; 42(6):943-56.

2. Mizuno K, Ueda A. The maturation and coordination of sucking, swallowing, and respiration in preterm infants. J Pediatr. 2003; 142(1):36-40.

3. Caetano LC, Fujinaga CI, Scochi CGS. Sucção não nutritiva em bebês prematuros: estudo bibliográfico. Rev Latinoam Enferm. 2003; 11(2):232-6.

4. Lau C. [Development of oral feeding skills in the preterm infant]. Arch Pediatr. 2007; 14(Suppl1):S35-41.

5. McCain GC, Gartside PS, Grennberg JM, Lott JW. A feeding protocol for healthy preterm infants that shortens time to oral feeding. J Pediatr. 2001; 139(3):374-9.

6. McCain GC. An evidence-based guideline for introducing oral feeding to healthy preterm infants. Neonatal Netw. 2003; 22(5):45-50.

7. Thoyre SM, Shaker CS, Pridham KF. The early feeding skills assessment for preterm infants. Neonatal Netw. 2005; 24(3):7-16

8. Lau C, Smith EO, Schanler RJ. Coordination of suck-swallow and swallow respiration in preterm infants. Acta Paediatr. 2003; 92(6):721-7.

9. Matias EL, Mello DFO. O seguimento fonoaudiológico e a participação materna na assistência ao recém-nascido pré-termo e de baixo peso. Fonoaudiol Bras. 2003; 2(3):60-4. 
10. Neiva FCB. Neonatologia: papel do fonoaudiólogo no berçário. In: Comitê de Motricidade oral: Sociedade Brasileira de Fonoaudiologia. Motricidade orofacial: como atuam os especialistas. São José dos Campos: Pulso; 2004. p. 225-34.

11. Neiva FCB, Leone CR. Sucção em recémnascidos pré-termo e estimulação da sucção. PróFono. 2006; 18(2):141-50.

12. Pickler RH, Reyna BA. A descriptive study of bottle-feeding opportunities in preterm infants. Adv Neonatal Care. 2003; 3(3):139-46.

13. Hack M, Estabrook MM, Robertson SS. Development of sucking rhythm in preterm infants. Early Hum Dev. 1985; 11(2):133-40.

14. Gewolb IH, Vice FL, Schweitzer-Kenney EL, Taciak VL, Bosma JF. Developmental patterns of rhythmic suck and swallow in preterm infants. Dev Med Child Neurol. 2001; 43(1):22-7.

15. Bu'Lock F, Woolridge MW, Baum JD. Development of co-ordination of sucking, swallowing and breathing: ultrasound study of term and preterm infants. Dev Med Child Neurol. 1990; 32(8):669-78. 16. Simão KC, Mallet NR, Sant'Anna GM, Ramos $J R$, Meio MD. Estimulação sensório-motora oral em neonatos prematuros com peso de nascimento inferior a 1501g. Fono Atual. 2001; 4(15):35-8.

17. Nyqvist KH, Sjöden $P$, Ewald U. The development of preterm infants' breastfeeding behavior. Early Hum Dev. 1999; 55(3):247-64.

18. Fucile S, Gisel E, Lau C. Oral stimulation accelerates the transition from tube to oral feeding in preterm infants. J Pediatr. 2002; 141(2):230-6.

19. Fucile S, Gisel E, Lau C. Effect of an oral stimulation program on sucking skill maturation of preterm infants. Dev Med Child Neurol. 2005; 47(3):158-62.

20. Boiron M, Da Nobrega L, Roux S, Henrot A, Saliba E. Effects of oral stimulation and oral support on non-nutritive sucking and feeding performance in preterm infants. Dev Med Child Neurol. 2007; 49(6):439-44.

21. Pereira MG. Métodos empregados em epidemiologia. In: Pereira MG. Epidemiologia: teoria e prática. Rio de Janeiro: Guanabara Koogan; 1995. p.269-88.
22. Rocha AD, Moreira MEL, Pimenta HP, Ramos JRM, Lucena SL. A randomized study of the efficacy of sensory-motor-oral stimulation and non-nutritive sucking in very low birthweight infant. Early Hum Dev. 2007; 83(6):385-8.

23. Xavier C. Assistência à alimentação de bebês hospitalizados. In: Basseto MCA, Brock R, Wajnstejn R. Neonatologia: um convite à atuação fonoaudiológica. São Paulo: Lovise; 1998. p.255-75. 24. Neiva FCB. Análise do padrão de sucção em RNT e RNPT em idade gestacional de 34 a 36 6/7 semanas. 1999. CD. [tese] São Paulo (SP): Universidade de São Paulo; 1999.

25. Medeiros $A M C$, Oliveira KRF, Bittencourt $A B$, Alves PCL, Araripe ABS, Cardoso MFR, Hashimoto OS. Caracterização da atuação em berçário neonatal: uma visão fonoaudiológica. In: Marchesan IQ, Zorzi J. Tópicos em fonoaudiologia 2002/2003. Rio de Janeiro: Revinter; 2003. p. 293-308.

26. Neiva FCB, Leone CR. Evolução do ritmo de sucção e influência da estimulação em prematuros. Pró-Fono. 2007; 19(3):241-8.

27. Yamamoto RCC, Keske-Soares M, Weinmann ARM. Características da sucção nutritiva na liberação da via oral em recém-nascidos pré-termo de diferentes idades gestacionais. Rev Soc Bras Fonoaudiol. 2009; 14(1):98-105.

28. Neiva FCB, Leone C, Leone CR. Non-nutritive sucking scoring system for preterm newborns. Acta Paediatr. 2008; 97(10):1370-5.

29. Bauer MA, Prade LS, Keske-Soares M, Haëffner LSB, Weinmann ARM. The oral motor capacity and feeding performance of preterm newborns at the time of transition to oral feeding. Braz $\mathrm{J}$ Med Biol Res. 2008; 41(10):904-7.

30. Amaizu N, Shulman RJ, Schanler RJ, Lau C. Maturation of oral feeding skills in preterm infants. Acta Paediatr. 2008; 97(1):61-7.

31. Pickler RH, Best AM, Reyna BA, Gutcher G, Wetzel PA. Predictors of nutritive sucking in preterm infants. J Perinatol. 2006; 26(11):693-9

32. Howe TH, Sheu CF, Hinojosa Jim, Jing L, Holzman IR. Multiple factors related to bottlefeeding performance in preterm infants. Nurs Res. 2007; 56(5):307-11

RECEBIDO EM: 27/072008

APROVADO EM: 14/10/2009

Endereço para correspondência:

Raquel Coube de Carvalho Yamamoto

Rua Rubem Martins Berta, 103

Santa Maria - RS

CEP: 97105-350

E-mail: raquelcoube@yahoo.com.br 